\title{
Doenças crônicas
}

As doenças crônicas são as principais causas de morte no mundo, às quais foram atribuídas 35 milhões de óbitos em 2005, quase $60 \%$ da mortalidade mundial e 45,9\% da carga global de doenças. Segundo a Organização Mundial da Saúde (OMS), se essa tendência for mantida, elas deverão responder por $73 \%$ dos óbitos e $60 \%$ da carga de doenças no ano 2020.

Nos países das Américas e no Caribe, as doenças crônicas chegam a ser a causa de $75 \%$ dos óbitos, sendo que as doenças cardiovasculares (DCV) são responsáveis por aproximadamente $30 \%$ das mortes, cujos principais fatores de risco são a hipertensão arterial, o tabagismo, o colesterol elevado, a obesidade, os hábitos alimentares não-saudáveis e o sedentarismo. Em 2000, estimativas indicaram que, nesses locais, a prevalência da hipertensão variou de 14\% a 40\% entre indivíduos na faixa de 34 a 64 anos, perfazendo um total de 140 milhões de hipertensos. Estimaram-se também, nas Américas e no Caribe, cerca de 35 milhões de pessoas com diabetes e calcula-se que serão 64 milhões até o ano de 2025. Essas duas condições acarretam um aumento constante na prevalência de DCVs, em particular a doença isquêmica do coração e o acidente vascular cerebral (AVC), bem como insuficiência renal, cegueira, entre outras.

A rápida ascensão das doenças não-transmissiveis representa um grande desfio para o setor de saúde em relação ao desenvolvimento global. Em países desenvolvidos já se reconhecem, há décadas, as ameaças dessas doenças, sendo cada vez mais preocupante a sua predominância nos países em desenvolvimento.

$\mathrm{Na}$ tentativa de modificar os comportamentos de risco, as intervenções inicialmente eram direcionadas apenas para os indivíduos. No início dos anos 1970, os programas de prevenção das doenças crônicas já começaram a tomar forma de projetos de intervenções comunitárias, que continuaram a se intensificar na década seguinte. Assim foram implementados alguns projetos sobre essas doenças, através da redução concomitante dos fatores de risco comuns.

As evidências obtidas mostram que o campo da prevenção é um ponto fundamental a ser abordado e que precisa ser aprofundado à medida que os programas são implementados e avaliados em cada contexto específico.

Programas bem-sucedidos são aqueles que adotam um modelo multidimensional e incorporam diversos níveis de ação, como políticas nacionais, ações comunitárias e melhoria do acesso aos serviços de saúde e aumento da resolubilidade.

Considerando-se que a população mundial está envelhecendo e as doenças crônicas são altamente prevalentes nos idosos, se nossos gestores em saúde, sejam eles públicos ou privados, não investirem seriamente em ações de promoção e prevenção, os custos dessas enfermidades ficarão impossíveis de serem pagos.

A Sociedade Brasileira de Patologia Clínica/Medicina Laboratorial (SBPC/ML), tendo conhecimento da sua importância e responsabilidade como uma instituição que promove apoio aos serviços da saúde auxiliando o diagnóstico, a prevenção, o tratamento e o controle das doenças que hoje têm grande impacto em nossa população, no seu 40ํㅡㄹ Congresso Brasileiro de Patologia Clínica/Medicina Laboratorial, dará ênfase especial à abordagem das doenças cônicas e ao envelhecimento. 